\title{
Two-year surgical review of elective hysterectomy for non-oncological indications: experience from a tertiary centre
}

\author{
John J. K. Annan ${ }^{1 *}$, Thomas O. Konney ${ }^{1}$, Gerald O. Asubonteng1, Wilfred S. Awortwi ${ }^{2}$
}

${ }^{1}$ Department of Obstetrics and Gynaecology, ${ }^{2}$ Department of Anaesthesiology, Komfo Anokye Teaching Hospital, School of Medicine and Dentistry, Kwame Nkrumah University of Science and Technology, Kumasi, Ghana

Received: 28 August 2020

Accepted: 08 October 2020

\section{*Correspondence:}

Dr. John J. K. Annan,

E-mail: judedoc2003@yahoo.co.uk

Copyright: (c) the author(s), publisher and licensee Medip Academy. This is an open-access article distributed under the terms of the Creative Commons Attribution Non-Commercial License, which permits unrestricted non-commercial use, distribution, and reproduction in any medium, provided the original work is properly cited.

\begin{abstract}
Background: This retrospective descriptive cross-sectional study was aimed at determining indications, surgical outcomes, complications and challenges of elective non-oncological hysterectomies performed at a tertiary referral centre over a 2-year period (1st December 2018 to 31st December 2019).

Methods: With ethical approval, the medical records of all eligible women were retrieved, reviewed and analyzed. Measures of central tendencies, frequencies and percentages were used to compute the variables.

Results: During the 2-year study period, a total of 245 elective non-oncological hysterectomies were performed. The age of the women ranged from 33 to 80 years with a mean age of 49.08 years; [standard deviation (SD): 8.88]. Women in the 40-49 year-old-age group constituted the majority $55.51 \%(n=136 / 245)$. Main indications were multinodular fibroid uterus (without menorrhagia), fibroid uterus with menorrhagia and genital prolapse. There was no case of laparoscopic hysterectomy. Majority $(98.78 \% ; n=242 / 245)$ of the hysterectomies were total hysterectomies. The commonest additional procedures performed was bilateral salpingo-oophorectomy $(31.84 \%$; $n=78 / 245)$. Intraoperative complication rates were low: $(0.40 \% ; n=1 / 245)$ for bowel injury, bladder injury and bleeding from an ovary. Regional anaesthesia was the commonest type of anaesthesia $(71.84 \% ; n=176 / 245)$. The primary surgeon was above the level of a specialist in $99.19 \%(n=243 / 245)$ of cases.

Conclusions: Most women had hysterectomy for non-oncological indications in their fourth and fifth decades of life on account of fibroid-related conditions and genital prolapse. There was no uptake of laparoscopic hysterectomy. Hysterectomies are generally safe in the hands of an experienced and skilled surgical team.
\end{abstract}

Keywords: Non-oncological hysterectomy, Fibroid, Adenomyosis, Menorrhagia, Chronic pelvic pain

\section{INTRODUCTION}

Hysterectomy has been a common gynaecological operation for generations, and it is the most common major gynaecological operation performed worldwide. ${ }^{1,2}$ being the second most frequent surgical operation performed on women after caesarean section. ${ }^{3}$ It is performed for oncological (malignant) and nononcological (benign) indications. It is considered the definitive treatment of various benign pelvic pathologies like leiomyoma, dysfunctional uterine bleeding (DUB), chronic pelvic pain, endometriosis, adenomyosis and uterovaginal prolapse as well as malignancies. Traditionally, hysterectomies have been performed either by the open abdominal route or by the vaginal route. In recent times, with advancements in technology, most high-income countries have engaged in laparoscopic hysterectomy for both benign and malignant pathologies. ${ }^{4,5}$ Furthermore, the technology trend has led to robotic-assisted hysterectomy. ${ }^{6-8}$ The advantages of laparoscopic and robotic-assisted hysterectomy include less post-operative morbidity, short hospital stay and early resumption of work after surgery. ${ }^{8}$ Hysterectomy rates for non-oncological indications in the developed 
world have also diminished owing to a generally more conservative approach that aims at uterine conservation such as the use of various endometrial ablation methods.

This trend in the uptake of hysterectomy has not been the same in most low and middle-income countries due mainly to socio-cultural and economic barriers and to the absence in most of these countries of training programs for laparoscopic hysterectomy. ${ }^{9-12}$ In our sub-region, hysterectomy rates for non-oncological indications are still high. A review of the literature revealed a paucity of local studies examining the indications and complications associated with non-oncological hysterectomy.

This study was aimed at determining the indications, surgical outcomes, complications and challenges of hysterectomies for non-oncological indications in a tertiary referral centre in Ghana over a two-year period (1st January 2018 to 31st December 2019).

The findings will help in planning, organization of health care services, staff training and patient education. We additionally aim to highlight and recommend application of novel uterine-preserving methods of managing benign gynaecological uterine conditions and reduce the incidence of non-oncologically indicated hysterectomies.

\section{METHODS}

\section{Study design, area and population}

This is a retrospective descriptive cross-sectional study on all elective hysterectomies performed for nononcological indications in the gynecology department of Komfo Anokye Teaching Hospital (KATH), Kumasi over the period 1st January 2018 to 31st December 2019.

KATH is a 1300 bed capacity hospital and is the second largest tertiary hospital in Ghana serving as the major referral centre for the middle and northern sectors of Ghana. It is also designated as a training and teaching facility for the Kwame Nkrumah University of Science and Technology School of Medicine and Dentistry (KNUST/KSMD), Kumasi, and offers specialised or scientific clinical care, research and teaching. Included in the study were women who underwent elective hysterectomy for non-oncological indications in the Obstetrics and Gynaecology Directorate of KATH, Kumasi over the period 1st January 2018 to $31 \mathrm{st}$ December 2019. The exclusion criteria were: women who underwent elective hysterectomy outside KATH, women who had hysterectomy for oncological indications at KATH, women who had emergency hysterectomy at KATH and women who met the inclusion criteria but had incomplete medical records.

\section{Data collection}

The medical records of all eligible women were retrieved, reviewed and analyzed by the investigators aided by a research assistant (a resident in the department). The resident was taken through training to ensure data extraction was efficient. A data capture form (proforma) designed for the purpose of this study was used to capture the data. Information extracted from the medical records included socio-demographic data and surgical information: mainly age, indication for hysterectomy, type of abdominal incision, type of hysterectomy (total or subtotal), and route (abdominal, vaginal or laparoscopic). Other data was any associated procedures, type of anaesthesia used, level of the primary surgeon and intraoperative complications.

\section{Data handling and analysis}

The data collected was coded and entered into a predesigned data collection proforma. No patient identifiable information was documented. The information was then entered onto a Microsoft Excel Spread sheet. The data was then cleaned and those with incomplete data excluded. The final data was then analysed using STATA version 10. The data was password protected and accessible to only the investigators. The analysis was focused on the indications and surgical outcomes of hysterectomy. In computing the sociodemographic features of the study participants, measures of central tendencies (mean, standard deviation and interquartile ranges) were used while frequencies and percentages were used to compute continuous variables and then summarized in tables.

\section{RESULTS}

\section{General characteristics}

During the 2-year study period, a total of 245 elective non-oncological hysterectomies were performed. 126 (51.43\%; $n=126 / 245)$ in 2018 and there was a slight decrease in numbers to $119(48.57 \% ; n=119 / 245)$ in 2019. The age of the participants ranged from 33 to 80 years with a mean age of 49.08 years; [standard deviation (SD): 8.88]. Women in the 40-49 year-old-age group constituted the majority $55.51 \%(\mathrm{n}=136 / 245)$ and $62.45 \%$ $(n=153 / 245)$ of cases were below 50 years old and $4.90 \%$ were more than 70 years (Table 1).

\section{Indications for hysterectomy}

The primary clinical indications for elective nononcological hysterectomies were assessed in our study (Table 2). Multinodular fibroid uterus (without menorrhagia) constituted the major $(42.85 \%, \mathrm{n}=105 / 245)$ primary indication for non-oncological hysterectomies in our series whilst fibroid uterus with menorrhagia constituted $33.06 \%(n=81 / 245)$ of the cases. Genital prolapse constituted $13.47 \% \quad(n=33 / 245)$ of the indications. Less common indications were chronic pelvic pain, endometrial hyperplasia, recurrent endometrial polyps in a postmenopausal woman, 
dysfunctional uterine bleeding and severe cervical dysplasia.

Table 1: Age distribution of women who had emergency hysterectomy.

\begin{tabular}{|lcc|}
\hline Age group (years) & $\begin{array}{l}\text { Frequency } \\
(\mathbf{N})\end{array}$ & $\begin{array}{l}\text { Percentage } \\
(\%)\end{array}$ \\
\hline $\mathbf{3 0 - 3 9}$ & 17 & 6.94 \\
\hline $\mathbf{4 0 - 4 9}$ & 136 & 55.51 \\
\hline $\mathbf{5 0 - 5 9}$ & 57 & 23.27 \\
\hline $\mathbf{6 0 - 6 9}$ & 23 & 9.38 \\
\hline $\mathbf{7 0 - 7 9}$ & 11 & 4.49 \\
\hline $\mathbf{8 0 - 8 9}$ & 1 & 0.41 \\
\hline Total & 245 & 100.00 \\
\hline
\end{tabular}

Table 2: Primary indication for elective non-oncological hysterectomies.

\begin{tabular}{|lll|}
\hline Indication & $\begin{array}{l}\text { Frequency } \\
(\mathbf{N})\end{array}$ & $\begin{array}{l}\text { Percentage } \\
(\%)\end{array}$ \\
\hline $\begin{array}{l}\text { Bulky multinodular } \\
\text { fibroid uterus }\end{array}$ & 105 & 42.85 \\
\hline $\begin{array}{l}\text { Fibroid uterus with } \\
\text { menorrhagia }\end{array}$ & 81 & 33.06 \\
\hline Genital prolapse & 33 & 13.47 \\
\hline Persistent ovarian cyst & 8 & 3.27 \\
\hline Chronic pelvic pain & 7 & 2.86 \\
\hline Endometrial hyperplasia & 6 & 2.45 \\
\hline Others** & 5 & 2.04 \\
\hline Total & 245 & 100.00 \\
\hline
\end{tabular}

Others**: 1 case of recurrent endometrial polyp, 3 cases of dysfunctional uterine bleeding and 1 case of severe cervical dysplasia

\section{Characteristics of elective non-oncological hysterectomies}

The characteristics of elective non-oncological hysterectomies in our series were assessed.

\section{Route of entry}

Majority of the hysterectomies $(87 \% ; n=212 / 245)$ were performed through the open abdominal route and 33\%; $(n=33 / 245)$ were by the vaginal route. There was no case of laparoscopic hysterectomy. All the vaginal hysterectomies were as a result of utero-vaginal prolapse. Out of the 212 abdominal hysterectomies, abdominal entry was through the low transverse skin incision in $169 / 212$ cases whilst $43 / 212$ were through a midline skin incision.

\section{Type of hysterectomy}

Majority $(98.78 \% ; \mathrm{n}=242 / 245)$ of the hysterectomies were total hysterectomies whilst $1.22 \%(n=3 / 245)$ were subtotal (supracervical) hysterectomies.
Table 3: Characteristics of hysterectomy.

\begin{tabular}{|c|c|c|}
\hline Variables & $\begin{array}{l}\text { Frequency } \\
(\mathbf{N})\end{array}$ & $\begin{array}{l}\text { Percentage } \\
(\%)\end{array}$ \\
\hline \multicolumn{3}{|l|}{ Route of hysterectomy } \\
\hline $\begin{array}{l}\text { Laparotomy } \\
\text { (abdominal) }\end{array}$ & 212 & 87 \\
\hline Vaginal & 33 & 13 \\
\hline Laparoscopy & 0 & 0 \\
\hline Total & 245 & 100 \\
\hline \multicolumn{3}{|l|}{ Type of hysterectomy } \\
\hline Total & 242 & 98.78 \\
\hline $\begin{array}{l}\text { Subtotal } \\
\text { (supracervical) }\end{array}$ & 3 & 1.22 \\
\hline Total & 245 & 100.00 \\
\hline \multicolumn{3}{|l|}{ Additional procedures } \\
\hline None & 95 & 38.77 \\
\hline $\mathrm{BSO}$ & 78 & 31.84 \\
\hline $\begin{array}{l}\text { Unilateral salpingo- } \\
\text { oophorectomy } \\
\text { (RSO+LSO) }\end{array}$ & 38 & 15.51 \\
\hline SSLFPFR $* *$ & 30 & 12.24 \\
\hline $\begin{array}{l}\text { McCall culdoplasty+ } \\
\text { perinorrhaphy }\end{array}$ & 2 & 0.82 \\
\hline Bowel repair & 1 & 0.41 \\
\hline Bladder repair & 1 & 0.41 \\
\hline Total & 245 & 100.00 \\
\hline \multicolumn{3}{|c|}{ Intra-operative complications } \\
\hline None & 242 & 98.80 \\
\hline Bladder injury & 1 & 0.40 \\
\hline Bowel injury & 1 & 0.40 \\
\hline Bleeding ovary & 1 & 0.40 \\
\hline Death & 0 & 0.00 \\
\hline Total & 245 & 100.00 \\
\hline \multicolumn{3}{|l|}{ Type of anaesthesia } \\
\hline Regional (spinal) & 176 & 71.84 \\
\hline General & 62 & 25.31 \\
\hline Regional and general & 7 & 2.85 \\
\hline Total & 245 & 100.00 \\
\hline \multicolumn{3}{|c|}{ Level of primary surgeon } \\
\hline Consultant & 56 & 22.86 \\
\hline Senior specialist & 43 & 17.55 \\
\hline Specialist & 144 & 58.78 \\
\hline Resident & 2 & 0.81 \\
\hline Total & 245 & 100.00 \\
\hline
\end{tabular}

SSLFPFR**: Sacrospinous ligament fixation and pelvic floor Repair

\section{Additional procedures}

The commonest additional procedures performed were bilateral salpingo-oophorectomy $(31.84 \% ; n=78 / 245)$, unilateral salpingo-oophorectomy $(15.51 \% ; n=38 / 245)$ and sacrospinous ligament fixation and pelvic floor repair (SSLFPFR) 12.24\% ( $n=30 / 245)$. In 38.33\% ( $n=95 / 245)$, no additional procedure was performed. 


\section{Intra-operative complications}

Intra-operative complication rates were low. Bowel injury $(0.40 \% ; \mathrm{n}=1 / 245)$, bladder injury $(0.40 \%$; $\mathrm{n}=1 / 245)$ and bleeding from an ovary $(0.40 \% ; \mathrm{n}=1 / 245)$ were the intra-operative complications noted.

\section{Type of anaesthesia and primary surgeon}

Regional anaesthesia was the commonest type of anaesthesia (71.84\%; $\mathrm{n}=176 / 245)$. General anesthesia constituted $25.31 \% \quad(n=62 / 245)$ and $2.85 \% \quad(n=7 / 245)$ were regional anaesthesia that were converted to general anaesthesia. The primary surgeon was above the level of a specialist in $99.19 \%(n=243 / 245)$ of cases and all these were assisted by residents.

\section{DISCUSSION}

Hysterectomy is the most common gynecological procedure in the world and is the most definitive treatment option for various diseases like dysfunctional uterine bleeding (DUB), leiomyoma, adenomyosis, chronic pelvic pain, uterine prolapse and malignancy. ${ }^{13}$ This procedure leads to removal of the uterus with complete termination of the child-bearing potential of the woman. Nowadays, the world is focusing on successful, effective, safe and cost-effective, minimally invasive treatment options for benign gynecological disorders as alternative to hyste-rectomy. ${ }^{14}$ This has questioned the justification for hysterectomy for non-oncological indications.

During the 2-year study period, a total of 245 elective non-oncological hysterectomies were performed: 126 (51.43\%) in 2018 and there was a slight decrease in numbers to $119(48.57 \%)$ in 2019 . Most of the women who underwent hysterectomy were in their fourth and fifth decades of life with a mean of 49.08 years (SD: 8.88]. Compared with other studies, the mean age of our study participants was higher than that reported by Kouam et al in Yaoundé (43.23 \pm 8.23 years), while others have reported an average age for hysterectomy of 49.9 \pm 12.6 years. ${ }^{15-17}$ Among our study population, $62.45 \%$ of the women were in the 30-49-year-old group. It implies a lot of relatively young women are having hysterectomies and ending their child-bearing potential. There are known adverse long-term outcomes of hysterectomy including pelvic organ prolapse, urinary incontinence, anal incontinence, bowel dysfunction, pelvic organ fistula and renal cell carcinoma. ${ }^{18}$

Therefore, there is the need to consider alternative uterine-conserving methods to manage these patients especially once their gynaecological conditions are not life-threatening. Medical options available include the use of selective progesterone receptor modulators (SPRMs) such as ulipristal acetate (UPA), aromatase inhibitors, gonadotropin releasing hormone analogues (GnRHa) and levonorgestrel releasing intrauterine system
(LNG-IUS). Additionally, interventional radiology options such as uterine artery embolization (UAE) and fibroid artery embolisation are well recognized uterinesparing (fertility-preserving) methods of treating fibroids. More recently, the introduction of ultrasound waves (MRgFUS) or radiofrequency (VizAblate $^{\mathrm{TM}}$ and Acessa $^{\mathrm{TM}}$ ) for uterine fibroid ablation has added to the options of minimal access treatment. ${ }^{19,20}$ These can be offered especially as an option to women wishing to conserve their reproductive function. Additionally, several endometrial ablative methods are also available to treat these women. However, most of these treatment modalities are not readily available in low-resourced countries as most healthcare facilities do not have the technical and financial capability to offer these services to their clients. In a few facilities where these services are offered, the cost may be beyond the average client. As such removal of the uterus becomes the most favourable option.

The main purpose of hysterectomy is to relieve symptoms and improve quality of life deteriorated by symptoms such as abnormal menstrual bleeding, uterine fibroids, dysmenorrhea, chronic pelvic pain, bowel and urinary symptoms or uterine prolapse. ${ }^{21}$ Therefore, assessing the suitability of the indications for hysterectomy is important. In our series, bulky, multinodular fibroid uterus (without menorrhagia) constituted the major $(42.85 \%)$ primary indication for non-oncological hysterectomies followed by fibroid uterus with menorrhagia (33.06\%). Therefore, fibroid-related indications constituted $75.91 \%$ of indications for nononcological hysterectomies in our series. This is consistent with other studies that reported that uterine fibroids are the most common indication for hysterectomy. ${ }^{22-26} \mathrm{We}$ believe most of these hysterectomies could have been avoided if there existed other uterine-saving interventions. Genital prolapse followed the fibroid-related indication, constituting $13.47 \%(n=33 / 245)$ of the indications. This subgroup of patients had various degrees of utero-vaginal prolapse and required vaginal hysterectomy. The same indications of uterine fibroid and genital prolapse topped the list of indications for hysterectomies in various studies. ${ }^{27-29}$ Less common indications in our series were chronic pelvic pain, endometrial hyperplasia, recurrent endometrial polyps in a postmenopausal women, dysfunctional uterine bleeding and severe cervical dysplasia.

All our hysterectomies were performed through the abdominal (87\%; $\mathrm{n}=212 / 245)$ and the vaginal routes $33 \% ;(n=33 / 245)$. There was no case of laparoscopic hysterectomy. The abdominal route has been the most popular route in most studies. In a Turkish study more than $90 \%$ of the hysterectomies were done by abdominal route. ${ }^{30}$ Total abdominal hysterectomy accounted for $82.7 \%$ of hysterectomies in another study from India. ${ }^{31}$ Additionally, most of the hysterectomies were performed through an abdominal route in accordance with a 
Canadian study (abdominal 78\%, vaginal 14\%, and laparoscopic $5.9 \%) .^{32}$

Hysterectomy can be performed as a minimally invasive surgical procedure such as laparoscopic hysterectomy and robotic surgery. This has become the modern method in most developed and developing countries. A study carried out in Quebec, Canada, showed that the proportion of hysterectomies done by laparoscopy increased over the years while vaginal hysterectomies remained stable. Therefore, the number of abdominal hysterectomies was declining and the technicality index was increasing in Quebec. This was attributed to an increased use of medical alternatives and the presence of gynecologists better trained in advanced laparoscopic surgery. ${ }^{33,34}$ The trend in the uptake of hysterectomy has not been the same in most low and middle-income countries due mainly to socio-cultural and economic barriers and to the absence in most of these countries of training programs for laparoscopic hysterectomy. ${ }^{9-12}$ There was no case of laparoscopic hysterectomy in our centre. Operative laparoscopy had not taken off in our centre due to initial lack of expertise and absence of an operative laparoscopic service. Recently an operative service is being set up and with more specialists acquiring the operative laparoscopic skill, the trend will change soon. Additionally, the bulky, multinodular sizes of the fibroids, previous multiple myomectomies with associated potential risks of surgery may be a disincentive to this modern surgical approach. We will still recommend attention being paid to minimal access surgery as this method is endowed with several advantages including less post-operative morbidity, short hospital stay and early resumption of work after surgery and reduced cost to the health service. Fear of complications of laparoscopic hysterectomy may obviate its general use but careful patient selection is imperative in order to reduce the potential complications.

Majority $(98.78 \% ; n=242 / 245)$ of the hysterectomies in our study were total hysterectomies whilst a minority $(1.22 \% ; \mathrm{n}=3 / 245)$ were subtotal (supracervical) hysterectomies. Proponents of subtotal hysterectomy report a lesser blood loss, a reduced need for blood transfusion, reduced operating time and reduced intra and postoperative complications such as fewer instances of damage to the urinary tract (bladder and ureters). ${ }^{35,36}$ However, total hysterectomy has the advantage of removing the development of malignancy in the cervical stump, the need for regular cytology and other associated problems such as bleeding or discharge associated with the residual cervical stump. Surgical complications associated with hysterectomy include injury to bladder, ureters, bowel or blood vessels. These complications are rare and are common in patients with previous abdominopelvic surgeries. In our patient population, there were no major complications that endanger the life of the patients. Bowel injury $(0.40 \% ; n=1 / 245)$, bladder injury $(0.40 \%$; $\mathrm{n}=1 / 245)$ and bleeding from an ovary $(0.40 \% ; \mathrm{n}=1 / 245)$ were the intra-operative complications noted. These complications were identified and immediately managed. Reduced intraoperative complications are usually associated with the skill and experience of the gynecologists, especially in patients who have had a previous surgical operation. ${ }^{37}$ The primary surgeon was above the level of a specialist in $99.19 \%(n=243 / 245)$ of cases and all these were assisted by residents. We believe that these low complication rates can be attributable to the level of expertise and experience of the primary surgeon. This has an advantage of improving training in the acquisition of the requisite skills of the trainees whilst not compromising on the quality of care offered to these women. The role of anaesthesia in the efficient performance of this major surgical procedure cannot be overemphasized. Regional anaesthesia was the commonest type of anaesthesia $(71.84 \% ; n=176 / 245)$ followed by general anesthesia $[25.31 \%(n=62 / 245)]$. In a few cases $2.85 \%(n=7 / 245)$ regional anaesthesia had to be converted to general anaesthesia. During hysterectomy, additional procedures such as concomitant elective or emergency bilateral or unilateral salpingo-oophorectomy may be required. In patients with utero-vaginal prolapse, SSLFPFR may be required. No additional procedure was performed in $38.33 \%(n=95 / 245)$ in our study. The commonest additional procedures performed were bilateral salpingo-oophorectomy $(31.84 \% ; n=78 / 245)$, unilateral salpingo-oophorectomy $(15.51 \% ; n=38 / 245)$ and SSLFPFR $12.24 \% \quad(n=30 / 245)$ for those who had vaginal hysterectomy for prolapse. Ovarian conservation is a major consideration during non-oncologically indicated hysterectomy especially in the menopausal woman. There are benefits of ovarian conservation, and at no age is there a clear benefit from prophylactic oophorectomy. In women who are not at risk for ovarian cancer or having related malignancy at time of surgery, even in postmenopausal women, ovarian conservation may lead to longer survival, and limits the need for hormonal replacement therapy.

The major debate surrounding non-oncological hysterectomies is the appropriateness of the indication. In a study to judge appropriateness of non-emergency and non-oncologic hysterectomies in USA, indications were often found to be inappropriate. ${ }^{38}$ Therefore, resort to medical management and use of uterine-conserving methods are invaluable measures to reduce the cost to patients and the healthcare service, morbidity, increased length of hospital stay and the potential psychological morbidity associated with loss of the uterus which some women perceive as making them incomplete once it is removed.

\section{Limitations}

This was a retrospective study. Besides this was a hospital-based study and the data collected were from a single institution; therefore, the results may not reflect the general trend of non-oncologic hysterectomy in Ghana. 


\section{CONCLUSION}

Most women had hysterectomy for non-oncological indications in their fourth and fifth decades of life with fibroid-related conditions and genital prolapse constituting the commonest indications. All hysterectomies were performed through the abdominal and vaginal routes with no uptake of laparoscopic hysterectomy. Hysterectomies are generally safe in the hands of an experienced and skilled surgical team. More consideration should be given to uterine-conserving methods in management of benign conditions instead to resorting to hysterectomy especially once these gynaecological conditions are not life-threatening.

\section{ACKNOWLEDGMENTS}

We would like to acknowledge all medical records and allied health staff for their cooperation in the conduct of this study. We thank the Department of Obstetrics and Gynaecology for the data. We also acknowledge the Institutional Review Board for Research and Development (IRB/R\&D) for granting ethical approval for the conduct of this study.

Funding: No funding sources

Conflict of interest: None declared

Ethical approval: The study was approved by the Institutional Ethics Committee

\section{REFERENCES}

1. Lowensteina L, Yarnitskyb D, Gruenwaldc I, Deutscha M, Sprecherb E, Gedaliac U. et al. Does hysterectomy affect genital sensation? Europ J Obstet Gynecol Reprod Biol. 2005;119,242-5.

2. Tommaso F, Mark W. Hysterectomy for benign disease. Obstet Gynecol. 2008;111:753-67.

3. Saini J, Kuczynski E, Gretz H. F, Sills ES. Supracervical hysterectomy versus total abdominal hysterectomy: perceived effects on sexual function. Bio Med Cent Wom Heal. 2002;1186-91.

4. Reich H, DeCaprio J, McGlynn F. Laparoscopic hysterectomy. J Gynecol Surg. 1989;5:213-6.

5. Malzoni M, Tinelli R, Cosentino F, Perone C, Rasile M, Iuzzolino D. et al. Total laparoscopic hysterectomy versus abdominal hysterectomy with lymphadenectomy for early stage endometrial cancer: A prospective randomized study. Gynecol Oncol. 2009;112:126-33.

6. Advincula AP, Song A. The role of robotic surgery in gynecology. Curr Opin Obstet Gynecol. 2007;19: 331-6.

7. Gaia G, Holloway RW, Santoro L, Ahmad S, Di Silverio E, Spinillo A. Robotic-assisted hysterectomy for endometrial cancer compared with traditional laparoscopic and laparotomy approaches: A systematic review. Obstet Gynecol. 2010;116:142231.
8. Ayala-Yáñez R, Olaya-Guzmán EJ, HaghenbeckAltamirano J. Robotics in gynecology: Why is this technology worth pursuing? Clin Med Insights Reprod Heal. 2013;7:71-7.

9. $\mathrm{Wu}$ ES, Jeronimo J, Feldman S. Barriers and challenges to treatment alternatives for early-stage cervical cancer in lower-resource settings. J Glob Oncol. 2017;3:572-82.

10. Schwarts M, Jeng C-J, Chuang LT. Laparoscopic surgery for gynecologic cancer in low-and middleincome countries (LMICs): An area of need. Gynecol Oncol Rep. 2017;20:100-2.

11. Johnston C, Ng JS, Manchanda R, Tsunoda AT, Chuang L. Variations in gynecologic oncology training in low (LIC) and middle income (MIC) countries (LMICs): Common efforts and challenges. Gynecol Oncol Rep. 2017;20:9-14.

12. Lenihan JP, Kovanda C, Seshadri-Kreaden U. What is the learning curve for robotic assisted gynecologic surgery? J Minim Invasive Gynecol. 2008;15:58994.

13. Gupta G, Kotasthane DS, Kotasthane VD. Hysterectomy: a clinico-pathological correlation of 500 cases. Intern J Gynecol Obstetet. 2009;14(1):1-5

14. Sharma C, Sharma M, Raina R, Soni A, Chander B, Verma S. Gynecological diseases in rural India: A critical appraisal of indications and route of surgery along with histopathology correlation of 922 women undergoing major gynecological surgery. J Mi Lif Heal. 2014;5(2):55-61.

15. Kouam L, Kongnyuy EJ, Ngassa P, Fomulu N, Wamba MT, Doh AS. Hysterectomy: A 12-year retrospective review in the Yaoundé University Teaching Hospital. Clinic Moth Chil Heal. 2005;2:347-50.

16. Okunade KS, Sekumade A, Daramola E, Oluwole AA. A 4-Year clinical review of elective hysterectomies at a university teaching hospital in Lagos, Nigeria. J Gynecol Surg 2017;33:193-7.

17. Ogunlaja OA, Fehintola AO, Akinola SE, Awotunde OT, Durodola AO, Ogunlaja IP et al. A clinical audit of hysterectomy in Bowen University Teaching Hospital, Ogbomoso, South West Nigeria. Trop J Obstet Gynaecol. 2016;33:64-9.

18. Forsgren C, Altman D. Long-term effects of hysterectomy: a focus on the aging patient. Agi Heal. 2013;9(2):179-87.

19. Khan AT, Shehmar M, Gupta JK. Uterine fibroids: Current perspectives. Int J Wome Heal. 2014;6:95114.

20. Donnez J, Dolmans MM. Uterine fibroid management: From the present to the future. Hum Reprod Upda. 2016;22:665-86.

21. Stewart EA. Uterine fibroids. Lancet 2001;357(9252):293-8

22. Nausheen F, Iqbal J, Bhatti FA, Khan AT, Sheikh S. Hysterectomy: The patients perspective. Anna Kin Edwa Medic Univ. 2004;10(4).

23. Tiwana KK, Nibhoria S, Monga T, Phutela R. Histopathological Audit of 373 Nononcological 
Hysterectomies in a Teaching Hospital. Patholog Res Int. 2014;2014:468715.

24. Abe E, Omo-Aghoja LO. A decade of hysterectomy in a tertiary hospital in urban Niger-Delta region of Nigeria. Nigerian J Clin Practice. 2008;11(4):359-63.

25. Leung PL, Tsang SW, Yuen PM. An audit on hysterectomy for benign diseases in public hospitals in Hong Kong. Hong Kong Med J. 2007;13(3):18793.

26. Khan AT, Shehmar M, Gupta JK. Uterine fibroids: Current perspectives. Int J Womens Health 2014;6: 95-114.

27. Sucheta KL, Manangi M, Madhu KP, Arun BJ, Nagaraj N. Hysterectomy: clinical profile, indications and postoperative complications. Int $\mathrm{J}$ Reprod Contracept Obstet Gynecol. 2016;5:2093-6.

28. Shaikh TA, Memon F, Memon Z. Hysterectomies; an audit at a tertiary care hospital. Profession Med J. 2011;18(1).

29. Juneja SK, Tandon P, Mohan B, Kaushal S. A change in the management of intractable obstetrical hemorrhage over 15 years in a tertiary care center. Int J Appl Basic Med Res. 2014;4(1):S17-9.

30. Aksu F, Gezer A, Oral E. Seventeen-year review of hysterectomy procedures in a university clinic in Istanbul 1985-2001. Arch Gynecol Obstet. 2004;270(4):217-22.

31. Pandey D, Sehgal K, Saxena A, Hebbar S, Nambiar J, Bhat RG. An audit of indications, complications, and justification of hysterectomies at a teaching hospital in India. Int J Reprod Med. 2014;(2014):1-6

32. Toma A, Hopman WM, Gorwill RH. Hysterectomy at a Canadian tertiary care facility: results of a one year retrospective review. Brit Med Centr Wome Heal. 2004;4(1):10.

33. Bernatchez-Laflamme SM, Bujold E, Roberge S, Laberge PY. Development of technicality indices of hysterectomies in Quebec. J Obstet Gynaecol Can. 2013;35:144-8.

34. Evans D, Burnett M. Audit of minimally invasive hysterectomy rates: A Canadian retrospective crosssectional database review. Hospit Practic Resear. 2018;3:1-5.

35. Greer I, Lang G, Patel N. The Management of Postpartum Haemorrhage. Aberdeen: Scottish Obstetric Guidelines and Audit Project. 1998.

36. Rishi R, Fay L, Mckenna P. A 27-Year Review of Obstetric Hysterectomy. J Obstet Gynaecol. 2003;23:(3):252-4.

37. Egbe TO, Kobenge FM, Arlette MMJ, Eta-Nkongho E, Nyemb JE, Enow MR. Prevalence and Outcome of Hysterectomy at the Douala General Hospital, Cameroon: A Cross-Sectional Study. Int J Surg Res Pract. 2018;5:092.

38. Broder MS, Kanouse DE, Mittman BS, Bernstein SJ. The appropriateness of recommendations for hysterectomy. Obstet Gynecol. 2000;95(2):199-205.

Cite this article as: Annan JJK, Konney TO,

Asubonteng GO, Awortwi WS. Two-year surgical review of elective hysterectomy for non-oncological indications: experience from a tertiary centre. Int J Reprod Contracept Obstet Gynecol 2020;9:4403-9. 